\title{
Gastric MALT lymphoma presented with primary perforation in an adolescent: a case report
}

\author{
Yu-Tang Chang ${ }^{1,5,6}$, Ming-Yii Huang ${ }^{2,7}$, Hsiang-Hung Shih ${ }^{3,8}$, Chun-Chieh Wu ${ }^{4,9}$, Tzu-Ying Lu ${ }^{2}$ and Pei-Chin Lin ${ }^{3,8^{*}}$
}

\begin{abstract}
Background: Primary lymphomas of the gastrointestinal tract are rare, accounting for only 1 to $4 \%$ of malignancies arising in the stomach, small intestine, or colon. The stomach is the most common extranodal site of lymphoma and gastric mucosa-associated lymphoid tissue (MALT) lymphoma accounts for $40 \%$ of primary gastric lymphoma. Gastric MALT lymphoma reaches its peak incidence between 50 to 60 years of age, therefore, it is rarely encountered in pediatric population. The presenting symptoms of gastric MALT lymphoma are usually nonspecific and primary perforation of gastric MALT lymphoma is uncommon.

Case presentation: A 12 year-old female presented with iron deficient anemia developed gastric perforation. Emergency laparoscopic repair of the perforation was performed and tissue pathology showed gastric MALT lymphoma infiltration. Helicobacter pylori eradication and radiotherapy were sequentially performed. Complete remission was achieved at two months after radiotherapy. To our best knowledge, she is the youngest patient with gastric MALT lymphoma reported in the literature.

Conclusion: Iron deficient anemia is a common presenting manifestation of malignancies in adulthood. In pediatric population, iron deficient anemia is usually caused by nutritional deficient or blood loss. In this case report, we present a teenaged female without previous gastric ulcer history who presented with a rare gastric tumor and an uncommon primary perforation. Even if there is an uncertainty about the exact diagnosis prior to the surgery, the strategy of stomach-preserving therapy by laparoscopy for primary perforation was successful and provided a good quality of life.
\end{abstract}

Keywords: Gastric MALT lymphoma, Laparoscopy, Perforation, Iron deficiency, Adolescent

\section{Background}

Extranodal marginal zone B cell lymphoma of mucosaassociated lymphoid tissue (MALT lymphoma), which was previously considered a low-grade lymphoma, is the predominant histological subtype of primary gastric lymphoma, representing $1-6 \%$ of primary gastric neoplasm, 5-7\% of all non-Hodgkin lymphomas, $40-50 \%$ of all gastric lymphomas, and $50-60 \%$ of all extranodal lymphomas [1-4]. The common symptoms of gastric MALT lymphoma include epigastric pain, nausea, vomiting, weight loss, and gastrointestinal bleeding $[2,3]$.

\footnotetext{
* Correspondence: cooleylin@gmail.com

${ }^{3}$ Department of Pediatrics, Kaohsiung Medical University Hospital, Kaohsiung 80756, Taiwan

${ }^{8}$ Department of Pediatrics, Faculty of Medical School, College of Medicine, Kaohsiung Medical University, Kaohsiung 80708, Taiwan

Full list of author information is available at the end of the article
}

However, the description of perforation at presentation is rare in the literature [5-7]. Herein, we present such a case with successful management in a female adolescent.

\section{Case presentation}

A 12-year-old girl was admitted with noticeable palor and dyspnea on exertion for the past two weeks. No specific medicine or family histories were reported. She visited local clinics and her hemogram showed a low hemoglobin value. Physical examination showed a palor and mild tachycardia $(110 \mathrm{bpm})$. Laboratory data taken in our hospital showed a hemoglobin level of $5.9 \mathrm{~g} / \mathrm{dL}$; mean corpuscular volume of $75.4 \mathrm{fl}$; C-reactive protein level of 1.02 $\mathrm{mg} / \mathrm{L}$; serum ferritin of $2.9 \mathrm{ng} / \mathrm{mL}$; serum iron level of $9 \mu \mathrm{g} / \mathrm{dL}$; and total iron binding capacity at $458.2 \mu \mathrm{g} / \mathrm{dL}$. She denied bloody stool or abdominal discomfort history. Iron tablet (100 mg bid) was prescribed. Stool examination

(c) The Author(s). 2019 Open Access This article is distributed under the terms of the Creative Commons Attribution 4.0 International License (http://creativecommons.org/licenses/by/4.0/), which permits unrestricted use, distribution, and 


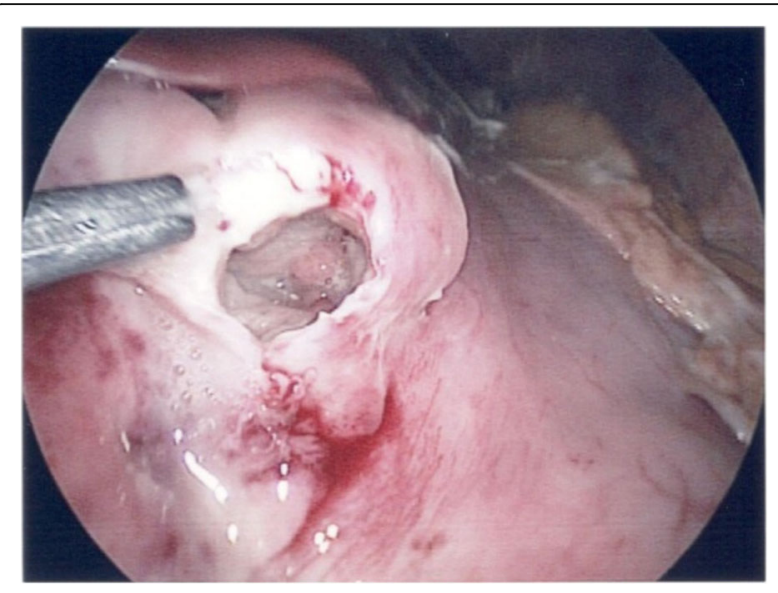

Fig. 1 Laparoscopic finding. Note the solitary perforation over the gastric body

showed a mild hemoccult-positive $(1+) .{ }^{13} \mathrm{C}$ urea breath test was a positive finding. Therefore, upper GI endoscopy was arranged.

However, $8 \mathrm{~h}$ prior to scheduled exams, patient complained of sudden onset of severe tenderness with involuntary guarding and rebounding pain involving the entire abdomen. Interpretation of standing view and left lateral decubitus abdominal film detected free intraperitoneal air, and peritonitis was confirmed. Because of the abnormal image findings, surgical intervention was advised and in light of hemodynamic stability, a laparoscopic approach was performed. After initial exploration of the peritoneal cavity, a burst perforation, approximately $1 \mathrm{~cm}$ in diameter, was noted over lower gastric body (Fig. 1). The edge of the perforation was excised, and simple closure was performed. The resected specimen was sent for pathological examination.

Histology confirmed the diagnosis of extranodal marginal zone B-cell lymphoma of MALT type. Section showed diffuse infiltration of small lymphocytes without residual normal architecture. The aggregation of tumor cells were composed of monocytoid cells with plasmacytoid and centrocyte-like cell differentiation (Fig. 2).
Immunohistochemically, these cells were positive for B-lymphocyte antigen cluster of differentiation (CD) 20, CD79a, and paired box protein Pax-5, but negative for CD3, CD5, CD10, B-cell lymphoma 2, CD30, terminal deoxynucleotidyl transferase, CD1a, c-Myc, and S100 (Fig. 3). Light-chain restriction for infiltrating plasma cells was not identified. Both Epstein-Barr encoding region in situ hybridization and cytomegalovirus were negative. The B-cell clonality exhibited monoclonality (Fig. 4).

Subsequently, a systemic workup for clinical staging, including lactate dehydrogenase (161 IU/L), $\beta 2$-microglobulin $(148.0 \mu \mathrm{g} / \mathrm{dL})$, hepatitis B virus (nonreactive), hepatitis C virus (negative), and human immunodeficiency virus (negative), was performed. Positron emission tomography-computed tomography (PET-CT) showed accumulation of fluorodeoxyglucose in the same area. CT, bone scan, and bone marrow biopsy were also performed, and no metastatic lesion was detected. The Lugano staging system was considered to be Stage IE.

After resuming an oral diet, a 2-weeks course of oral antibacterial treatment (clarithromycin $500 \mathrm{mg}$ plus amoxicillin $500 \mathrm{mg}$ twice a day for 7 days followed by metronidazole $500 \mathrm{mg}$ twice a day for another 7 days) plus 4 weeks esomeprazole ( $40 \mathrm{mg}$ daily) were prescribed for Helicobacter pylori infection eradication. Endoscopy was scheduled 4 weeks after operation and showed a deep and large ulcer over anterior wall of the body with convergence of thickened mucosal folds (Fig. 5a). Biopsy samples were again obtained and consistent with extranodal marginal zone lymphoma of MALT. Therefore, involved field radiation therapy was delivered to the stomach (30 Gy in 20 fractions given over 4 weeks). There were no gastrointestinal side effects noted during and after radiotherapy.

A follow-up endoscopy was performed at 4 months after operation, and showed a broad-based healed scar with rugae interruption (Fig. 5b). The histological evaluation of biopsy specimen showed absent plasma cells and small lymphoid cells and complete histological remission was achieved at 2 months after radiotherapy. During a 1-year follow-up at our outpatient clinic, she has remained free of symptoms and without relapse. The timeline was shown in Additional file 1.

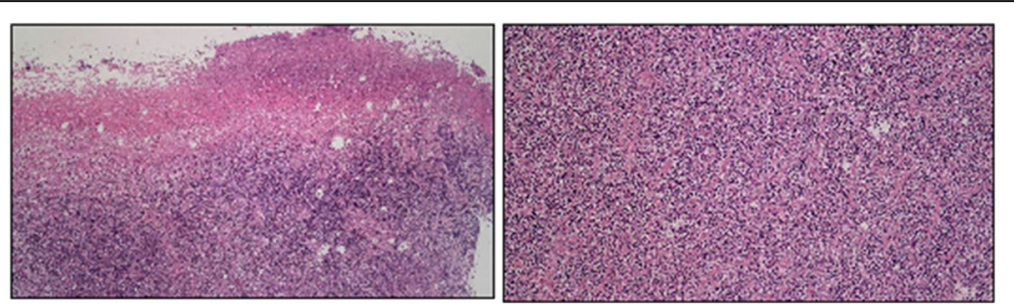

Fig. $2 \mathrm{HE}$ stain of gastric tissue. At low power field (left), the specimen shows an ulcerated surface with fibrinopruvulent and necrotic materials coated, and mixed inflammatory cells infiltrate in the deep submucosal or muscular layers. However, there are some large, atypical lymphoid cells scattered distributed in the background at high power field (right) 


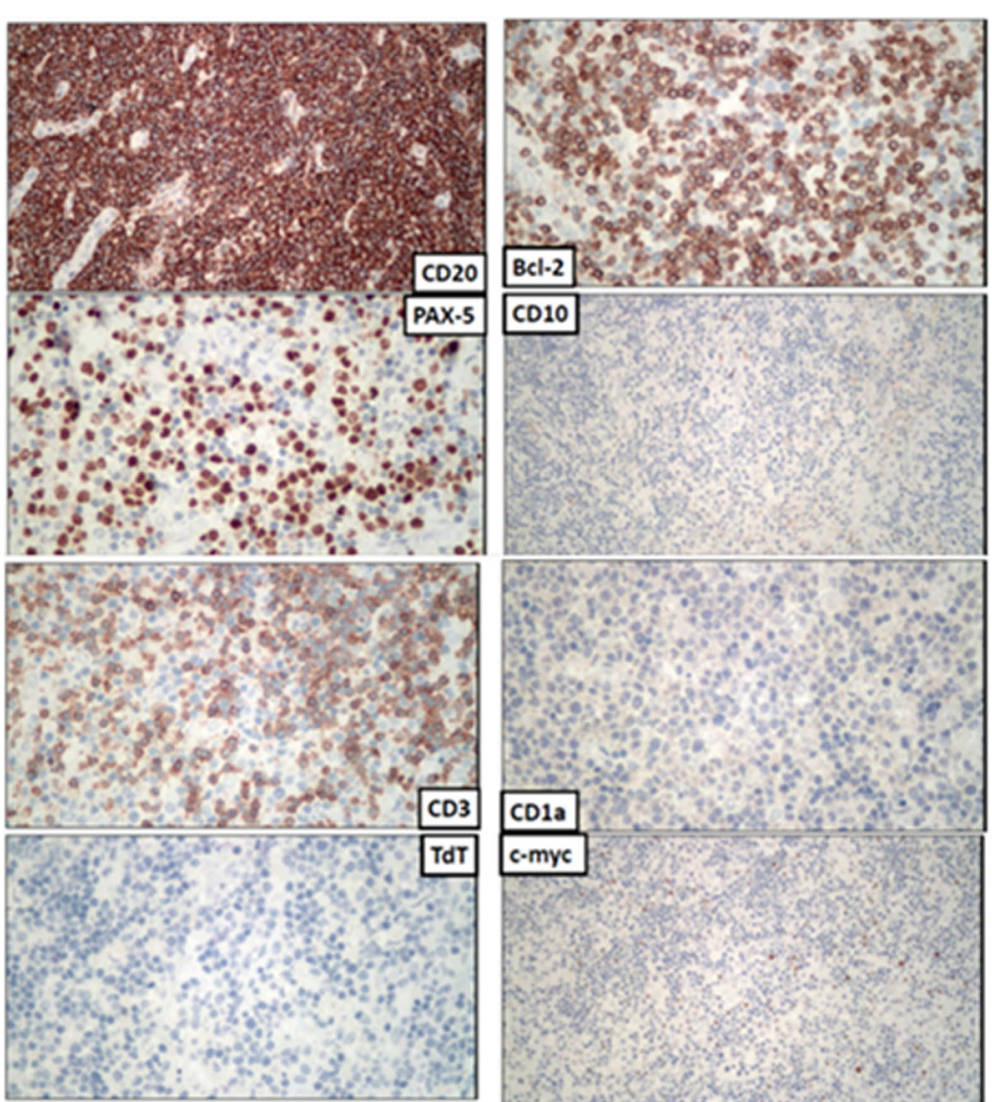

Fig. 3 Immunohistochemistry stain of gastric tissue. These atypical lymphoid cells are immunoreactive for CD20, PAX-5, Bcl-2, and negative for CD3, CD10, CD1a, TdT and c-myc

\section{Discussion and conclusions}

Since MALT lymphoma is characterized as "low-grade" (or indolent) and has a natural history of slow progression, most cases occur in individuals 50 years or older, with disease being most common in the sixth decade [2-4]. To our best knowledge, this 12-year-old girl is the youngest patient with gastric MALT lymphoma reported in the literature.

$H$ pylori has been identified as the cause of chronic gastritis with consequent acquisition of lymphatic tissue, and up to $98 \%$ of gastric MALT lymphoma are second to $H$ pylori infection [8]. According to the clinical

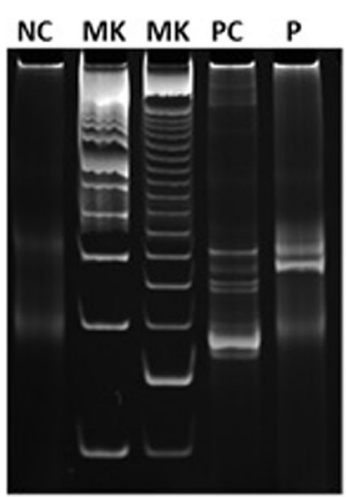

IGK Tube A

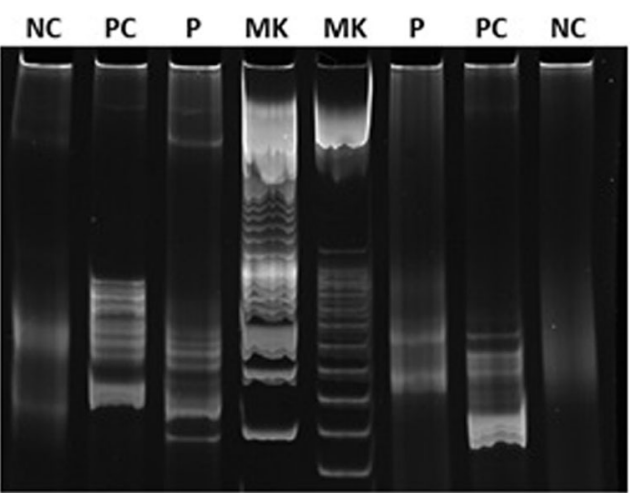

IGK Tube B and IGH Tube B

Fig. 4 Polymerase chain reaction-based clonality study for immunoglobulin gene rearrangement. Monoclonal were detected by BIOMED2 IGK Tube A, IGK Tube B and IGH Tube B reactions. (NC: negative control, MK: marker, PC: positive control, P: patient) 

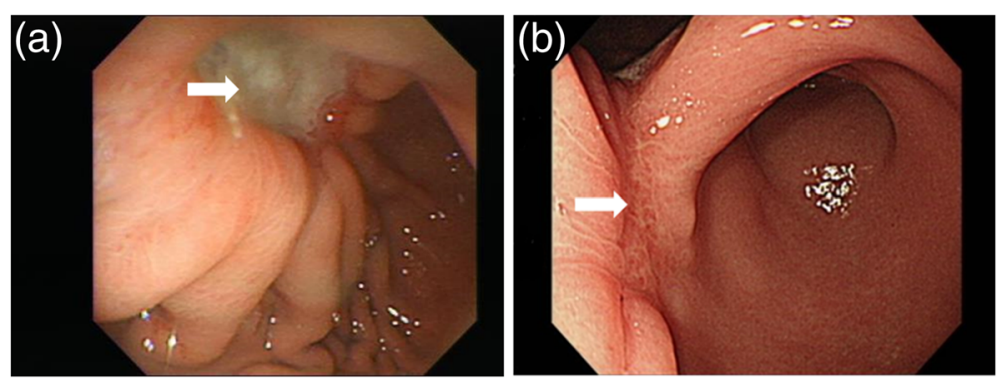

Fig. 5 Endoscopic findings. a Endoscopic finding after operation. An ulcerative lesion over lower gastric body close the gastric angle can be seen. Suture line was observed at the bottom of the crater (white arrow). b Endoscopic finding after radiotherapy. The ulcerative lesion was healed with scar formation (white arrow)

practice guidelines recommended by the European Society for Medical Oncology (ESMO) Guidelines Working Group [9], $H$ pylori eradication is the first-time treatment in any case irrespective of $H$ pylori status and lymphoma stage [2, 8], and lead to a complete remission in $50-90 \%$ of cases [4]. Those patients revealing persistence or progression of lymphoma despite successful $H$ pylori eradication should receive radiation or chemotherapy [1]. Surgery usually does not play a role in the therapy of gastric MALT lymphoma, however, complications such as perforation or bleeding that cannot be controlled endoscopically may require surgical intervention $[2,8]$.

The infiltration of MALT lymphoma is mostly confined to the mucosa, and only $10 \%$ of infiltration invade deeply beyond muscularis propria [4]. Therefore, primary perforation is a rare complication of gastric MALT lymphoma. On reviewing the literature starting from the first description of MALT lymphoma in 1983 [10], only 4 cases have been reported [5-7, 11]. Of these 4 patients, 3 were men, ranging in age from 24 to 84 years. Due to the rare cases reported in the literature, the management for primary perforation of gastric MALT lymphoma has been gastrectomy with lymphadenectomy [5-7]. However, in the case of low-grade lymphoma, immediate radical resection may be unnecessary and an organ-preserving therapy would provide a better quality of life [12]. Simple closure of perforated gastric MALT lymphoma (followed by clinical practice guidelines according to the ESMO Guidelines Working Group) seems to be an acceptable treatment. As experience with minimally invasive surgery has expanded in perforated peptic ulcer, laparoscopy is both feasible and safe for a gastric perforation by MALT lymphoma.

Radiotherapy usually offers a curative option to patients with $H$ pylori negative or refractory to $H$ pylori eradication [1]. In the present case, radiotherapy was given because of deep invasion and patient's young age. The major concern of radiotherapy for the patient was the risk of radiotherapy-related gastric perforation and bleeding, about $4 \%$ reported in the literature $[1,13]$. However, involved field radiotherapy with moderate-dose (30-Gy) may improve the target coverage and reduce radiation dose. Since gastric carcinoma is also associated with $H$ pylori gastritis, $5 \%$ of metachronous gastric carcinoma occurred after remission of gastric MALT lymphoma and the risk of development of gastric carcinoma in patients with gastric MALT lymphoma were shown to be 6 times higher than in the general population $[4,14,15]$. Due to the diagnosis at the young age in the present case, long-term follow-up is mandatory for detection of metachronous gastric carcinoma at an early stage.

In pediatric population, iron deficient anemia is usually caused by nutritional deficient or blood loss. This case presents a relatively uncommon clinical problem. Even if there is an uncertainty about the exact diagnosis prior to the surgery, a stomach-preserving therapy by minimally invasive surgery is acceptable and should provide a good quality of life.

\section{Additional file}

Additional file 1: Timeline. (PDF $650 \mathrm{~kb})$

Abbreviation

MALT: Mucosa-associated lymphoid tissue

Acknowledgements

Thank you to Ms. Serena Tseng for her review of the manuscript.

Funding

This study had no funding source.

Availability of data and materials

The dataset supporting the conclusions of this article is included within the article.

Authors' contributions

YTC treated the patient and drafted the initial manuscript. PCL treated the patient and reviewed and revised the manuscript. HHS treated the patient and reviewed and revised the manuscript. CCW reviewed the pathology and revised the manuscript. MYH and TYL designed the radiotherapy protocol and revised the manuscript. All authors read and approved the final manuscript. 
Ethics approval and consent to participate

Not applicable.

\section{Consent for publication}

Written informed consent was obtained from the parents of the patient for publication of this Case report and any accompanying images. A copy of the written consent is available for review by the Editor-In-Chief of this journal.

\section{Competing interests}

The authors declare that they have no competing interests.

\section{Publisher's Note}

Springer Nature remains neutral with regard to jurisdictional claims in published maps and institutional affiliations.

\section{Author details}

'Division of Pediatric Surgery, Department of Surgery, Kaohsiung Medical University Hospital, Kaohsiung 80756, Taiwan. ${ }^{2}$ Department of Radiation Oncology, Kaohsiung Medical University Hospital, Kaohsiung 80756, Taiwan. ${ }^{3}$ Department of Pediatrics, Kaohsiung Medical University Hospital, Kaohsiung 80756, Taiwan. ${ }^{4}$ Department of Pathology, Kaohsiung Medical University Hospital, Kaohsiung Medical University, Kaohsiung 80708, Taiwan. ${ }^{5}$ Graduate Institute of Medicine, College of Medicine, Kaohsiung Medical University, Kaohsiung 80708, Taiwan. 'Department of Surgery, Faculty of Medical School, College of Medicine, Kaohsiung Medical University, Kaohsiung 80708, Taiwan. ${ }^{7}$ Department of Radiation Oncology, Faculty of Medical School, College of Medicine, Kaohsiung Medical University, Kaohsiung 80708, Taiwan. ${ }^{8}$ Department of Pediatrics, Faculty of Medical School, College of Medicine, Kaohsiung Medical University, Kaohsiung 80708, Taiwan. ${ }^{9}$ Department of Pathology, Faculty of Medical School, College of Medicine, Kaohsiung Medical University, Kaohsiung 80708, Taiwan.

Received: 22 February 2018 Accepted: 11 February 2019

Published online: 19 February 2019

\section{References}

1. Lim HW, Kim TH, Choi IJ, Kim CG, Lee JY, Cho SJ, Eom HS, Moon SH, Kim DY. Radiation therapy for gastric mucosa-associated lymphoid tissue lymphoma: dose-volumetric analysis and its clinical implications. Radiat Oncol J. 2016;34(3):193-201.

2. Wang YG, Zhao LY, Liu CQ, Pan SC, Chen XL, Liu K, Zhang WH, Yang K, Chen $X Z$, Zhang $B$, et al. Clinical characteristics and prognostic factors of primary gastric lymphoma: a retrospective study with 165 cases. Medicine (Baltimore). 2016;95(31):e4250.

3. Al-Sheneber II, Shibata H. Primary gastric lymphoma. Cancer Control. 1997:4(3):245-52

4. Nakamura S, Sugiyama T, Matsumoto T, lijima K, Ono S, Tajika M, Tari A, Kitadai $Y$, Matsumoto $H$, Nagaya T, et al. Long-term clinical outcome of gastric MALT lymphoma after eradication of helicobacter pylori: a multicentre cohort follow-up study of 420 patients in Japan. Gut. 2012;61(4):507-13.

5. El Asmar A, Khattar F, Alam M, El Rassi Z. Spontaneous perforation of primary gastric B-cell lymphoma of MALT: a case report and literature review. Clin Case Rep. 2016;4(11):1049-52.

6. Lopez-Zamudio J, Ramirez-Gonzalez LR, Nunez-Marquez J, Fuentes Orozco C, Gonzalez Ojeda A, Leonher-Ruezga KL. Gastric perforation by MALT lymphoma. Case report. Cir Cir. 2015;83(3):217-21.

7. Chuang SS, Diss T, Li CF. Primary gastric small lymphocytic lymphoma with perforation. Histopathology. 2006;49(6):656-8.

8. $\quad$ Fischbach W. MALT lymphoma: forget surgery? Dig Dis. 2013;31(1):38-42.

9. Zucca E, Copie-Bergman C, Ricardi U, Thieblemont C, Raderer M, Ladetto M, Group EGW. Gastric marginal zone lymphoma of MALT type: ESMO clinical practice guidelines for diagnosis, treatment and follow-up. Ann Oncol. 2013; 24(Suppl 6):vi144-8.

10. Isaacson P, Wright DH. Malignant lymphoma of mucosa-associated lymphoid tissue. A distinctive type of B-cell lymphoma. Cancer. 1983;52(8):1410-6.

11. Shimada S, Gen T, Okamoto H. Malignant gastric lymphoma with spontaneous perforation. BMJ Case Rep. 2013;2013.
12. Fischbach W, Schramm S, Goebeler E. Outcome and quality of life favour a conservative treatment of patients with primary gastric lymphoma. Z Gastroenterol. 2011;49(4):430-5.

13. Otsuka T, Noda T, Yokoo M, Ibaraki K. Recurrent gastric perforation as a late complication of radiotherapy for mucosa-associated lymphoid tissue lymphoma of the stomach. Intern Med. 2008;47(15):1407-9.

14. Ono S, Kato M, Takagi K, Kodaira J, Kubota K, Matsuno Y, Komatsu Y, Asaka M. Long-term treatment of localized gastric marginal zone B-cell mucosa associated lymphoid tissue lymphoma including incidence of metachronous gastric cancer. J Gastroenterol Hepatol. 2010;25(4):804-9.

15. Capelle LG, de Vries AC, Looman CW, Casparie MK, Boot H, Meijer GA, Kuipers EJ. Gastric MALT lymphoma: epidemiology and high adenocarcinoma risk in a nation-wide study. Eur J Cancer. 2008;44(16):2470-6.

\section{Ready to submit your research? Choose BMC and benefit from:}

- fast, convenient online submission

- thorough peer review by experienced researchers in your field

- rapid publication on acceptance

- support for research data, including large and complex data types

- gold Open Access which fosters wider collaboration and increased citations

- maximum visibility for your research: over $100 \mathrm{M}$ website views per year

At BMC, research is always in progress.

Learn more biomedcentral.com/submissions 